\title{
Usefulness of combining serum uric acid and high-sensitivity C-reactive protein for risk stratification of patients with metabolic syndrome in community-dwelling women
}

\author{
Ryuichi Kawamoto $\cdot$ Yasuharu Tabara $\cdot$ Katsuhiko Kohara $\cdot$ \\ Tetsuro Miki · Tomo Kusunoki · Shuzo Takayama • \\ Masanori Abe $\cdot$ Tateaki Katoh $\cdot$ Nobuyuki Ohtsuka
}

Received: 27 June 2011 / Accepted: 11 September 2011/Published online: 9 March 2013

(C) The Author(s) 2013. This article is published with open access at Springerlink.com

\begin{abstract}
Metabolic syndrome (MetS) is associated with an increased risk of major cardiovascular events. In women, increased uric acid (UA) levels are associated with MetS and its components. High-sensitivity C-reactive protein (hsCRP) levels are also associated with MetS, and hsCRP levels could be modulated by UA. We investigated whether combining UA and hsCRP levels are independently associated with MetS and insulin resistance in Japanese community-dwelling women. From a single community, we recruited 1,097 women
\end{abstract}

\author{
R. Kawamoto · T. Kusunoki - S. Takayama - M. Abe \\ Department of Community Medicine, Ehime University \\ Graduate School of Medicine, Ehime 791-0295, Japan \\ e-mail: kusunoki.tomo.mm@ehime-u.ac.jp \\ S. Takayama \\ e-mail: spya6yq9@rhythm.ocn.ne.jp \\ M. Abe \\ e-mail: masaben@m.ehime-u.ac.jp \\ R. Kawamoto $(\bowtie) \cdot$ T. Kusunoki · T. Katoh · N. Ohtsuka \\ Department of Internal Medicine, Seiyo Municipal Nomura \\ Hospital, 9-53 Nomura, Nomura-cho, Seiyo-city, \\ Ehime 797-1212, Japan \\ e-mail: rykawamo@yahoo.co.jp \\ T. Katoh \\ e-mail: tkatoh@m.ehime-u.ac.jp \\ N. Ohtsuka \\ e-mail: ohtsukan@hotmail.com \\ Y. Tabara $\cdot$ K. Kohara $\cdot$ T. Miki \\ Department of Geriatric Medicine, Ehime University Graduate \\ School of Medicine, Ehime 791-0295, Japan \\ e-mail: tabara@m.ehime-u.ac.jp \\ K. Kohara \\ e-mail:koharak@m.ehime-u.ac.jp \\ T. Miki \\ e-mail: tmiki@m.ehime-u.ac.jp
}

$(63 \pm 12$ years) during their annual health examination, and examined the cross-sectional relationship between UA, hsCRP, and MetS and insulin resistance, which was evaluated by homeostasis of minimal assessment of insulin resistance. Of these subjects, 218 women $(19.9 \%)$ had MetS. Multiple linear regression analysis was performed to evaluate the contribution of each confounding factor for MetS and insulin resistance, both UA and hsCRP as well as age and alcohol consumption, were independently and significantly associated with MetS and insulin resistance. The adjusted-odds ratios (95\% confidence interval) for MetS across tertiles of UA and hsCRP were 1.00, 1.45 (0.95-2.22), and 2.61 (1.74-3.93), and 1.00, 1.80 (1.18-2.74), and 3.23 (2.15-4.85), respectively. In addition, the combination increased UA, and hSCRP was also a significant and independent determinant for MetS and insulin resistance. In direction associations, we also observed a synergistic effect between these two molecules ( $F=2.76, P=0.027$ ). These results suggested that combined assessment of UA and hsCRP levels provides incremental information for risk stratification of patients with MetS, independent of other confounding factors in community-dwelling women.

Keywords Uric acid - C-reactive protein $\cdot$ Metabolic syndrome $\cdot$ Insulin resistance $\cdot$ Women

\section{Introduction}

Metabolic syndrome (MetS), a clustering of cardiovascular risk factors such as visceral obesity, insulin resistance, hypertension, glucose intolerance, hypertriglyceridemia, and low high-density lipoprotein cholesterol (HDL-C) levels, is a major worldwide public health problem. In Japan, it is $13.3 \%$ in men and $11.5 \%$ in women [1]. MetS increases the risk of 
diabetes, atherosclerotic disease [2], and cardiovascular disease (CVD) [3]. With the continuous increase in obesity prevalence in Japan, MetS may become even more common.

Recently, results from a meta-analysis of individual participant data from 54 long-term prospective studies demonstrated that high-sensitivity C-reactive protein (hsCRP) is also an inflammatory marker and independent predictor of CVD such as coronary heart disease, ischemic stroke, and vascular and non-vascular mortality [4]. Several studies have demonstrated that many people with MetS have an elevated hsCRP concentration [5], which may predict their risk for future adverse events [6].

Increased serum uric acid (UA) in humans is also associated with systemic inflammation [7], endothelial dysfunction [8], hypertension [9], CVD, and CVD mortality [10]. Despite a strong association between serum UA level and various CVD in humans, UA is not considered as having a pathogenetic role in these conditions, and instead, is considered as biologically inert or possibly anti-inflammatory because it could function as an antioxidant [11]. However, Koga et al. [12] reported that UA showed a significant correlation with hsCRP, suggesting a possible effect between these two key markers. Furthermore, UA is more strongly associated with MetS in women than in men [13]. However, there are few reports on the relationship between combining $\mathrm{UA}$ and CRP, and MetS in Japanese women.

The aim of this study was to determine whether combining UA and hsCRP levels are independently associated with MetS and insulin resistance by examining crosssectional data from Japanese community-dwelling women.

\section{Methods}

\section{Subjects}

Participants were recruited at the time of their annual health examination in a rural town with a total population of 11,136 (as of April 2002) and located in Ehime prefecture, Japan, in 2002. Among the 4,738 female aged 19-90 years in this population, a random sample of 1,713 $(36.2 \%)$ subjects was recruited. For all these individuals, overnight fasting plasma sample were available for measuring hsCRP. The final study sample compromised 1,097 residents. This study was approved by the ethics committee of Ehime University School of Medicine, and written informed consent was obtained from each subjects.

Evaluation of risk factors

Information on demographic characteristics and risk factors was collected using the clinical files. Body mass index was calculated by dividing weight (in $\mathrm{kg}$ ) by the square of the height (in $\mathrm{m}$ ). We measured blood pressure with an appropriate-sized cuff on the right upper arm of the subjects in the sedentary position using an automatic oscillometric blood pressure recorder (BP-103i; Colin, Aichi, Japan) while they were seated after having rested for at least $5 \mathrm{~min}$. Other characteristics such as smoking, alcohol habit, and medication, were investigated by individual interviews that were conducted using a structured questionnaire. Smoking status was classified into non-current smoker and current smokers. The daily alcohol consumption was measured using the Japanese liquor unit in which a unit corresponds to $22.9 \mathrm{~g}$ of ethanol, and the participants were classified into neverdrinkers, occasional drinkers $(<1 \mathrm{U} /$ day $)$, and light-heavy drinkers ( $\geq 1 \mathrm{U} /$ day). Total cholesterol (T-C), triglycerides (TG), HDL-C, fasting plasma glucose (FPG), and UA were measured by the laboratory of health examination center during an overnight fast of more than $11 \mathrm{~h}$. The plasma sample were immediately frozen and stored at $-80{ }^{\circ} \mathrm{C}$ until measurements were taken by the laboratory of our department. The plasma hsCRP concentration was measured using a Behring BN II nephelometer (Dade Behring Inc., Marburg, Germany) and the inter- and intra-assay coefficient variations were 3.2 and $6.7 \%$, respectively. Low-density lipoprotein cholesterol (LDL-C) level was calculated by the Friedewald formula [14]. Individuals with TG levels $\geq 400 \mathrm{mg} / \mathrm{dL}$ were excluded. Homeostasis of model assessment of insulin resistance (HOMA-IR) was calculated from FPG and IRI levels using the following formula: [FPG $(\mathrm{mg} / \mathrm{dL}) \times$ IRI $(\mathrm{mU} / \mathrm{mL})] / 405$ [15]. Insulin resistance was defined as a HOMA-IR $\geq 2.6[16]$.

\section{Metabolic syndrome}

We applied condition-specific cutoff points for MetS based on the modified criteria of the National Cholesterol Education Program's Adult Treatment Panel (NCEP-ATP) II report [17]. MetS was defined as subjects with at least three or more of the following five conditions: (1) obesity: BMI $\geq 25.0 \mathrm{~kg} / \mathrm{m}^{2}$ according to the guidelines of the Japanese Society for the Study of Obesity (waist circumference was not available in this study) [18]; (2) raised BP with a systolic blood pressure $(\mathrm{SBP}) \geq 130 \mathrm{mmHg}$ and/or diastolic blood pressure (DBP) $\geq 85 \mathrm{mmHg}$, and/or current treatment for hypertension; (3) Hypertriglyceridemia with a TG level $\geq 150 \mathrm{mg} / \mathrm{dL}$; (4) low HDL cholesterolemia with a HDL-C $<50 \mathrm{mg} / \mathrm{dL}$ in women and/or current treatment for dyslipidemia; and (5) impaired fasting glucose with a FPG level $\geq 100 \mathrm{mg} / \mathrm{dL}$ and/or current treatment for diabetes mellitus.

Statistical analysis

Data are presented as the mean \pm standard deviation (SD) unless otherwise specified, and in the cases of parameters 
with non-normal distributions (TG, FPG, HOMA-IR, and hsCRP), the data are shown as median (interquartile range) values. In all analyses, parameters with non-normal distributions were used after log-transformation. Statistical analysis was performed using PASW Statistics 17.0 (Statistical Package for Social Science Japan, Inc., Tokyo, Japan). Correlations between UA and hsCRP were determined using Pearson's correlation. Multiple linear regression analysis was used to evaluate the contribution of confounding factors (e.g., age, alcohol consumption, current smoking status, UA, and hsCRP) for number of MetS components and HOMA-IR. Subjects were divided into three groups based on tertiles of UA and hsCRP, and differences among the groups categorized by each tertile of UA and hsCRP were analyzed by ANOVA for continuous variables or the $\chi^{2}$ test for categorical variables. Multiple logistic regression analyses were used to evaluate the contribution of confounding factors for MetS and insulin resistance (HOMA-IR $\geq 2.6$ ), and further used to also evaluate the contribution of each tertile of UA and hsCRP for MetS, each component of MetS, and insulin resistance. The combining effect of UA and hsCRP was evaluated using multiple logistic regression analyses adjusted for the following parameters: age, current smoking status, alcohol consumption, UA, and hsCRP. The synergistic effect of $\mathrm{UA}$ and hsCRP was evaluated using a general linear model (Fig. 1). A $P$ value $<0.05$ was considered significant.

\section{Results}

Characteristics of subjects

The characteristics of the subjects categorized according to tertiles of UA and hsCRP are illustrated in Table 1. The study included 1,097 women, aged $63 \pm 12$ (range 21-88) years. Age, BMI, SBP, DBP, the presence of antihypertensive medication, TG, LDL-C, FPG, and HOMA-IR were significantly higher in relation to the higher tertiles of UA and hsCRP, but HDL-C were significantly lower in the higher tertiles. Alcohol consumption increased significantly in correlation with an increase in tertile of UA, and history of CVD increased with tertile of hsCRP. There was no inter-group difference in current smoking status, and the presence of antilipidemic and antidiabetic medication.

Association between various characteristics, and MetS and insulin resistance

UA levels significantly increased with hsCRP $(r=0.285$, $P<0.001$; data not shown). As shown in Table 2, multiple linear regression analysis was used to evaluate the
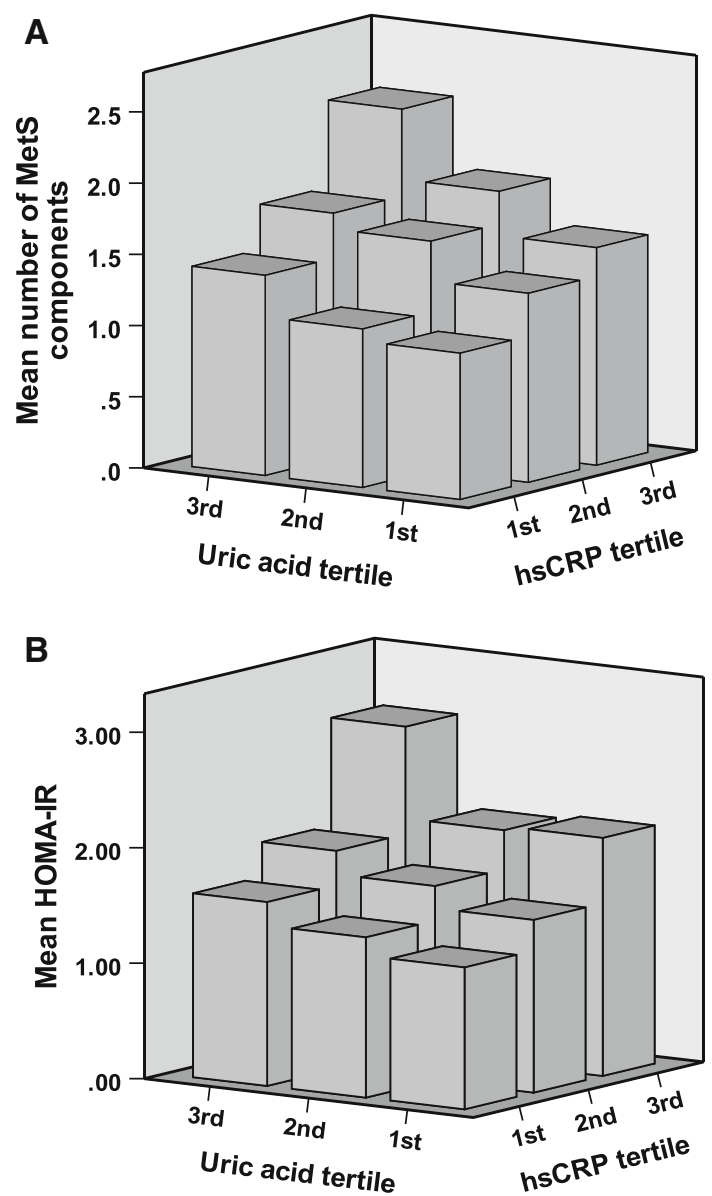

Fig. 1 Combining effect of UA and hsCRP. a Mean accumulating number of metabolic syndrome (MetS) components: obesity, raised blood pressure, hypertriglyceridemia, low HDL cholesterolemia, and impaired fasting glucose. b HOMA-IR. Study subjects were divided into three groups (tertiles) according to the UA and hsCRP levels

contribution of each confounding factor for MetS and insulin resistance. Both UA and hsCRP as well as age and alcohol consumption were independently significantly associated with number of MetS, and both UA and hsCRP was associated with insulin resistance. In addition, after adjustment for history of CVD and medication (i.e., antihypertensive, antilipidemic, and antidiabetic medication), these results were similar.

Prevalence and adjusted-odds ratio for MetS, its components, and insulin resistance in relation to tertiles of UA and hsCRP

Table 3 shows prevalence and the risk for MetS and abnormalities of its components in relation to tertiles of UA and hsCRP among 1,097 women. Of these, 218 women $(19.9 \%)$ had MetS. As shown in Table 3, after adjustments for age, current smoking status, and alcohol consumption, the prevalence rate of MetS, its components, and insulin resistance increased significantly in relation to the higher 
Table 1 Characteristics of subjects categorized according to tertiles of uric acid and hsCRP

\begin{tabular}{|c|c|c|c|c|c|c|c|c|}
\hline \multirow[t]{2}{*}{ Characteristics } & \multicolumn{4}{|c|}{ Tertile of uric acid } & \multicolumn{4}{|l|}{ Tertile of hsCRP } \\
\hline & $\begin{array}{l}1 \text { st } N=366 \\
<4.0\end{array}$ & $\begin{array}{l}\text { 2nd } N=379 \\
4.0-4.8\end{array}$ & $\begin{array}{l}3 \mathrm{rd} N=352 \\
>4.8 \mathrm{mg} / \mathrm{dL}\end{array}$ & $P$ value & $\begin{array}{l}1 \mathrm{st} N=414 \\
<0.032\end{array}$ & $\begin{array}{l}\text { 2nd } N=353 \\
0.032-0.071\end{array}$ & $\begin{array}{l}3 \mathrm{rd} N=330 \\
>0.071 \mathrm{mg} / \mathrm{dL}\end{array}$ & $P$ value \\
\hline Age (years) & $62 \pm 12$ & $62 \pm 12$ & $65 \pm 11$ & 0.003 & $60 \pm 13$ & $64 \pm 11$ & $65 \pm 10$ & $<0.001$ \\
\hline $\begin{array}{l}\text { Body mass index } \\
\left(\mathrm{kg} / \mathrm{m}^{2}\right)\end{array}$ & $22.3 \pm 3.0$ & $23.4 \pm 3.1$ & $24.6 \pm 3.6$ & $<0.001$ & $21.9 \pm 2.8$ & $23.6 \pm 3.0$ & $25.0 \pm 3.6$ & $<0.001$ \\
\hline $\begin{array}{l}\text { Current smoking } \\
\text { status }(\%)^{\mathrm{a}}\end{array}$ & 0.8 & 1.6 & 2.6 & 0.186 & 1.7 & 1.4 & 1.8 & 0.914 \\
\hline $\begin{array}{l}\text { Alcohol consumption } \\
(\%)^{\mathrm{b}}\end{array}$ & $69.1 / 28.7 / 2.2$ & $62.8 / 31.4 / 5.8$ & $61.9 / 29.8 / 8.2$ & 0.006 & $60.1 / 32.6 / 7.2$ & $66.3 / 28.9 / 4.8$ & $68.5 / 27.9 / 3.6$ & 0.074 \\
\hline History of CVD (\%) & 5.5 & 6.6 & 8.5 & 0.261 & 4.8 & 5.9 & 10.3 & 0.010 \\
\hline $\begin{array}{l}\text { Systolic blood } \\
\text { pressure (mmHg) }\end{array}$ & $135 \pm 23$ & $138 \pm 23$ & $143 \pm 23$ & $<0.001$ & $135 \pm 23$ & $140 \pm 23$ & $142 \pm 23$ & $<0.001$ \\
\hline $\begin{array}{l}\text { Diastolic blood } \\
\text { pressure }(\mathrm{mmHg})\end{array}$ & $78 \pm 12$ & $80 \pm 11$ & $82 \pm 12$ & $<0.001$ & $79 \pm 12$ & $81 \pm 12$ & $81 \pm 11$ & $<0.001$ \\
\hline $\begin{array}{l}\text { Antihypertensive } \\
\text { medication (\%) }\end{array}$ & 14.8 & 26.6 & 35.8 & $<0.001$ & 17.9 & 27.8 & 33.0 & $<0.001$ \\
\hline $\begin{array}{l}\text { Triglycerides (mg/ } \\
\text { dL) }\end{array}$ & $80(61-107)$ & $89(67-119)$ & $105(76-144)$ & $<0.001$ & $83(60-111)$ & $91(70-125)$ & $100(74-144)$ & $<0.001$ \\
\hline $\begin{array}{l}\text { HDL cholesterol } \\
(\mathrm{mg} / \mathrm{dL})\end{array}$ & $67 \pm 15$ & $65 \pm 16$ & $63 \pm 16$ & 0.005 & $68 \pm 16$ & $64 \pm 15$ & $61 \pm 15$ & $<0.001$ \\
\hline $\begin{array}{l}\text { LDL cholesterol } \\
(\mathrm{mg} / \mathrm{dL})\end{array}$ & $121 \pm 29$ & $126 \pm 30$ & $131 \pm 30$ & $<0.001$ & $118 \pm 28$ & $130 \pm 29$ & $132 \pm 30$ & $<0.001$ \\
\hline $\begin{array}{l}\text { Antilipidemic } \\
\text { medication (\%) }\end{array}$ & 5.5 & 6.9 & 7.7 & 0.486 & 4.8 & 6.8 & 8.8 & 0.098 \\
\hline $\begin{array}{l}\text { Fasting plasma } \\
\text { glucose }(\mathrm{mg} / \mathrm{dL})\end{array}$ & $91(86-98)$ & 92 (87-99) & $95(89-102)$ & 0.003 & $90(85-97)$ & $92(87-100)$ & $95(89-104)$ & $<0.001$ \\
\hline HOMA-IR & $\begin{array}{l}1.22 \\
\quad(0.76-1.72)\end{array}$ & $\begin{array}{l}1.35 \\
(0.94-1.95)\end{array}$ & $\begin{array}{l}1.71 \\
\quad(1.17-2.61)\end{array}$ & $<0.001$ & $\begin{array}{l}1.14 \\
\quad(0.77-1.63)\end{array}$ & $\begin{array}{l}1.44 \\
\quad(0.99-2.09)\end{array}$ & $\begin{array}{l}1.70 \\
\quad(1.14-2.82)\end{array}$ & $<0.001$ \\
\hline $\begin{array}{l}\text { Antidiabetic } \\
\text { medication }(\%)\end{array}$ & 3.6 & 2.4 & 3.7 & 0.533 & 1.7 & 3.4 & 4.8 & 0.050 \\
\hline Uric acid $(\mathrm{mg} / \mathrm{dL})$ & $3.4 \pm 0.5$ & $4.4 \pm 0.2$ & $5.7 \pm 0.7$ & $<0.001$ & $4.1 \pm 0.9$ & $4.5 \pm 1.0$ & $4.8 \pm 1.1$ & $<0.001$ \\
\hline hsCRP (mg/dL) & $\begin{array}{l}0.031 \\
\quad(0.016-0.060)\end{array}$ & $\begin{array}{l}0.042 \\
\quad(0.022-0.077)\end{array}$ & $\begin{array}{l}0.064 \\
\quad(0.032-0.124)\end{array}$ & $<0.001$ & $\begin{array}{l}0.018 \\
\quad(0.012-0.024)\end{array}$ & $\begin{array}{l}0.047 \\
\quad(0.038-0.059)\end{array}$ & $\begin{array}{l}0.135 \\
\quad(0.094-0.294)\end{array}$ & $<0.001$ \\
\hline
\end{tabular}

Data presented are mean \pm standard deviation. Data for triglycerides, fasting plasma glucose, HOMA-IR, and hsCRP were skewed and are presented as median (interquartile range) values, and were log-transformed for analysis

hSCRP high-sensitivity C-reactive protein, $C V D$ cardiovascular disease, $H D L$ high-density lipoprotein, LDL low-density lipoprotein, HOMA-IR homeostasis of model assessment of insulin resistance

* $P$ value from ANOVA for continuous variables or from $\chi^{2}$ test for categorical variables

${ }^{a}$ Current smoking status was classified into non-current smoker and current smokers

b Alcohol consumption was measured using a Japanese liquor unit where $1 \mathrm{U}$ corresponds to $22.9 \mathrm{~g}$ of ethanol [never-drinkers, occasional drinkers $(<1 \mathrm{U} /$ day), and light-heavy drinkers ( $\geq 1 \mathrm{U} /$ day)]

tertiles of UA and hsCRP. The ORs (95\% CI) for MetS across the tertiles of UA and hsCRP were 1.00, 1.45 (0.95-2.22), and 2.61 (1.74-3.93), and 1.00, 1.80 (1.18-2.74), and 3.23 (2.15-4.85), respectively. The ORs of UA were significantly high for the MetS components of obesity, raised blood pressure, hypertriglyceridemia, and ORs of hsCRP were significantly high for obesity, hypertriglyceridemia, low HDL cholesterolemia, and impaired fasting glucose. The ORs for insulin resistance also increased significantly in relation to both UA and hsCRP.
Combining effects of UA and hsCRP on mean accumulating number of MetS components and insulin resistance

We assessed the statistical significance of the combining relationship using multiple logistic regression analyses adjusted for the confounding factors (Table 4). The odds ratio of an increased tertile of UA and hsCRP was a significant and independent determinant for MetS and insulin resistance. 
Table 2 Multiple linear regression analysis for number of MetS components and HOMA-IR

\begin{tabular}{|c|c|c|c|c|}
\hline \multirow[t]{2}{*}{ Characteristics } & \multicolumn{2}{|c|}{ Number of MetS components } & \multicolumn{2}{|l|}{ HOMA-IR } \\
\hline & $\beta$ ( $P$ value $)$ & $\beta$ ( $P$ value $)$ & $\beta$ ( $P$ value $)$ & $\beta$ ( $P$ value $)$ \\
\hline Age (years) & $0.240(<0.001)$ & $0.230(<0.001)$ & $0.019(0.541)$ & $-0.031(0.333)$ \\
\hline Current smoking status, $N(\%)$ & $-0.011(0.701)$ & $-0.012(0.676)$ & $-0.006(0.846)$ & $-0.004(0.887)$ \\
\hline Alcohol consumption, $N(\%)$ & $-0.068(0.020)$ & $-0.066(0.025)$ & $-0.044(0.148)$ & $-0.032(0.293)$ \\
\hline History of CVD & - & $0.060(0.032)$ & - & $0.000(0.991)$ \\
\hline Medication & - & - & - & $0.170(<0.001)$ \\
\hline Uric acid (mg/dL) & $0.189(<0.001)$ & $0.188(<0.001)$ & $0.190(<0.001)$ & $0.161(<0.001)$ \\
\hline hsCRP (mg/dL) & $0.180(<0.001)$ & $0.178(<0.001)$ & $0.229(<0.001)$ & $0.220(<0.001)$ \\
\hline$R^{2}$ & $0.187(<0.001)$ & $0.191(<0.001)$ & $0.119(<0.001)$ & $0.143(<0.001)$ \\
\hline
\end{tabular}

Metabolic syndrome (MetS) components were defined as the following conditions: obesity, raised blood pressure, hypertriglyceridemia, low HDL cholesterolemia, and impaired fasting plasma glucose. Medications include antihypertensive, antilipidemic, and antidiabetic medication

\section{Synergistic effects of UA and hsCRP}

In addition to their direct associations, we observed a synergistic effect between UA and hsCRP. In Fig. 1, subjects were divided into three groups according to the tertiles of UA and hsCRP levels. We assessed the statistical significance of the synergistic relationship using a general linear model with the following confounding factors: age, current smoking, and alcohol consumption. The interaction between increased UA and hsCRP was a significant and independent determinant for the accumulation of MetS components $(F=2.76, P=0.027)$, in addition to their direct associations (UA tertile, $F=18.6, P<0.001$; hsCRP tertile, $F=26.1, P<0.001$ ).

\section{Discussion}

In 1,097 community-dwelling women, we determined the prevalence rate of MetS, as defined by the modified NCEPATP III criteria [17], and examined the association between UA and hsCRP, and MetS and its components. MetS was common, occurring in $19.9 \%$ of women. In women, the prevalence rate of MetS increased significantly in relation to UA and hsCRP, even after adjusting for age, smoking status, and alcohol consumption, and the ORs of MetS increased dose dependently with increasing tertiles of UA and hsCRP. In addition, we demonstrated that the ORs of MetS and insulin resistance were significantly increased in relation to combining UA and hsCRP. To our knowledge, this is the first study to indicate these associations of UA and hsCRP with MetS and insulin resistance in about 1,000 community-dwelling women.

Elevated CRP was associated with increased odds of MetS after adjusting for potential confounding factors [19]. In a rural Chinese population, the prevalence of MetS increased progressively with elevated CRP levels
$(P<0.001$ for trend). In the highest quartile of CRP levels $(>1.50 \mathrm{mg} / \mathrm{L})$, the risk for MetS was substantially higher (0R 5.97; $95 \%$ CI 4.75-7.51) compared with that in the lowest quartile of CRP levels $(\leq 0.33 \mathrm{mg} / \mathrm{L})$ after adjustment for age, sex, geographic location, lifestyle factors, level of education attained, and family history of chronic diseases [19]. We have also reported that after adjusting for age, smoking status, LDL-C, creatinine and history of diabetes mellitus, the ORs $(95 \% \mathrm{CI})$ of the sex-specific quartiles of UA for MetS were 1.0, 1.04 (0.56-1.94), 2.35 (1.30-4.22), and $2.20(1.16-4.20)$ in women [13]. In this study, increased UA and hsCRP were independently and significantly associated with the prevalence of MetS and insulin resistance.

The mechanisms by which UA reflect the risk for MetS are not completely understood. In the past, most authorities have not considered UA as having a pathogenetic role of CVD and have viewed UA as biologically inert or possibly anti-inflammatory because it could function as an antioxidant [11]. However, recent studies have challenged this viewpoint and it has been reported that both elevated UA may also reflect systemic inflammation [20] and is closely associated with the pathogenesis of MetS and type 2 diabetes [21] which impairs insulin signaling in the liver, muscle, and adipose tissues [22], and carotid intima-media thickness which is a surrogate maker [23]. Kang et al. [24] demonstrated that UA-induced changes in vascular proliferation and function may be mediated by de novo production of CRP in human vascular cells. Nakagawa et al. [25] recently reported that UA reduces levels of endothelial nitric oxide (NO) which is a key mediator of insulin action and increases blood flow to skeletal muscle and enhances glucose uptake. In addition, UA involves activation of the renin angiotensin system [26] and direct actions on endothelial and vascular smooth muscle cells [24]. Moreover, UA was also found to have a significant causal role in MetS that was induced experimentally by fructose [27]. 
Table 3 The prevalence and adjusted ORs for MetS, its components, and insulin resistance in relation to the tertiles of uric acid and hsCRP

\begin{tabular}{|c|c|c|c|c|c|c|c|c|}
\hline \multirow[t]{2}{*}{ Characteristics } & \multicolumn{4}{|c|}{ Tertile of uric acid } & \multicolumn{4}{|c|}{ Tertile of hsCRP } \\
\hline & $\begin{array}{l}1 \text { st } \\
N=366 \\
<4.0\end{array}$ & $\begin{array}{l}\text { 2nd } N=379 \\
4.0-4.8\end{array}$ & $\begin{array}{l}3 \mathrm{rd} N=352 \\
>4.8 \mathrm{mg} / \mathrm{dL}\end{array}$ & $P$ value & $\begin{array}{l}1 \mathrm{st} \\
N=414 \\
<0.032\end{array}$ & $\begin{array}{l}\text { 2nd } N=353 \\
0.032-0.071\end{array}$ & $\begin{array}{l}3 \mathrm{rd} N=330 \\
>0.071 \mathrm{mg} / \mathrm{dL}\end{array}$ & $P$ value \\
\hline MetS & $43(11.7 \%)$ & $66(17.4 \%)$ & $109(31.0 \%)$ & $<0.001$ & $42(10.1 \%)$ & $68(19.3 \%)$ & $108(32.7 \%)$ & $<0.001$ \\
\hline Adjusted OR (95\% CI) & Reference & $1.45(0.95-2.22)$ & $2.61(1.74-3.93)$ & $<0.001$ & Reference & $1.80(1.18-2.74)$ & $3.23(2.15-4.85)$ & $<0.001$ \\
\hline \multicolumn{9}{|l|}{ Components of MetS } \\
\hline Obesity & $63(17.2 \%)$ & $105(27.7 \%)$ & $157(44.6 \%)$ & $<0.001$ & $62(15.0 \%)$ & $103(29.2 \%)$ & $160(48.5 \%)$ & $<0.001$ \\
\hline Adjusted OR (95\% CI) & Reference & $1.63(1.13-2.35)$ & $2.85(1.98-4.10)$ & $<0.001$ & Reference & $2.15(1.49-3.09)$ & $4.55(3.17-6.54)$ & $<0.001$ \\
\hline Raised blood pressure & $\begin{array}{l}219 \\
\quad(59.8 \%)\end{array}$ & $253(66.8 \%)$ & $261(74.1 \%)$ & $<0.001$ & $\begin{array}{l}249 \\
\quad(60.1 \%)\end{array}$ & $244(69.1 \%)$ & $240(72.7 \%)$ & 0.001 \\
\hline Adjusted OR (95\% CI) & Reference & $1.41(0.99-1.98)$ & $1.75(1.20-2.55)$ & 0.012 & Reference & $1.06(0.75-1.50)$ & $1.05(0.72-1.51)$ & 0.945 \\
\hline Hypertriglyceridemia & $32(8.7 \%)$ & $47(12.4 \%)$ & $81(23.0 \%)$ & $<0.001$ & $37(8.9 \%)$ & $49(13.9 \%)$ & $74(22.4 \%)$ & $<0.001$ \\
\hline Adjusted OR (95\% CI) & Reference & $1.41(0.87-2.28)$ & $2.61(1.65-4.12)$ & $<0.001$ & Reference & $1.36(0.86-2.17)$ & $2.12(1.36-3.31)$ & 0.003 \\
\hline $\begin{array}{l}\text { Low HDL } \\
\text { cholesterolemia }\end{array}$ & $64(17.5)$ & $91(24.0)$ & $86(24.4)$ & 0.040 & $66(15.9 \%)$ & $78(22.1 \%)$ & $97(29.4 \%)$ & $<0.001$ \\
\hline Adjusted OR (95\% CI) & Reference & $1.44(1.00-2.08)$ & $1.31(0.89-1.94)$ & 0.132 & Reference & $1.35(0.93-1.95)$ & $1.93(1.33-2.79)$ & 0.002 \\
\hline $\begin{array}{l}\text { Impaired fasting } \\
\text { glucose }\end{array}$ & $82(22.4 \%)$ & $91(24.0 \%)$ & $113(32.1 \%)$ & 0.007 & $75(18.1 \%)$ & $97(27.5 \%)$ & $114(34.5 \%)$ & $<0.001$ \\
\hline Adjusted OR (95\% CI) & Reference & $1.01(0.71-1.44)$ & $1.30(0.91-1.85)$ & 0.253 & Reference & $1.51(1.06-2.15)$ & $1.93(1.35-2.75)$ & 0.001 \\
\hline Insulin resistance $\mathrm{e}^{\mathrm{a}}$ & $36(9.8 \%)$ & $47(12.4 \%)$ & $90(25.6 \%)$ & $<0.001$ & $31(7.5 \%)$ & $49(13.9 \%)$ & $93(28.2 \%)$ & $<0.001$ \\
\hline Adjusted OR (95\% CI) & Reference & $1.14(0.71-1.83)$ & $2.28(1.47-3.55)$ & $<0.001$ & Reference & $1.14(0.71-1.83)$ & $2.28(1.47-3.55)$ & $<0.001$ \\
\hline
\end{tabular}

Study subjects were divided into three groups (tertiles) according to uric acid and hsCRP levels. Adjusted for age, current smoking status, and alcohol consumption

$O R$ odds ratio, $C I$ confidence interval

${ }^{\text {a }}$ Insulin resistance was defined as HOMA-IR $\geq 2.6$

Table 4 Multiple logistic regression analysis for MetS and insulin resistance

\begin{tabular}{|c|c|c|c|c|c|c|}
\hline \multirow[t]{2}{*}{ Characteristics } & \multicolumn{3}{|c|}{ MetS adjusted OR (95\% CI) } & \multicolumn{3}{|c|}{ Insulin resistance ${ }^{\mathrm{a}}$ adjusted OR $(95 \% \mathrm{CI})$} \\
\hline & hsCRP-1st & hsCRP-2nd & hsCRP-3rd & hsCRP-1st & hsCRP-2nd & hsCRP-3rd \\
\hline Uric acid-1st & Reference & $1.26(0.57-2.87)$ & $3.31(1.51-7.24)$ & Reference & $1.22(0.52-2.87)$ & $1.48(0.58-3.80)$ \\
\hline Uric acid-2nd & $1.93(0.87-4.30)$ & $3.31(1.64-6.68)$ & $3.89(1.89-8.01)$ & $1.70(0.72-4.01)$ & $1.91(0.87-4.19)$ & $3.56(1.68-7.58)$ \\
\hline Uric acid-3rd & $3.36(1.52-7.43)$ & $4.35(2.11-8.99)$ & $9.25(4.81-17.8)$ & $3.11(1.34-7.21)$ & $3.60(1.66-7.77)$ & $8.92(4.54-17.6)$ \\
\hline
\end{tabular}

Metabolic syndrome (MetS) was defined as having three or more of the following conditions: obesity, raised blood pressure, hypertriglyceridemia, low HDL cholesterolemia, and impaired fasting plasma glucose. Adjusted for the following parameters: age, current smoking status, and alcohol consumption

${ }^{\text {a }}$ Insulin resistance was defined as HOMA-IR $\geq 2.6$

Excessive fructose intake induces hyperuricemia and features of MetS, such as an increase in ambulatory BP and TG, but a decrease in HDL-C in healthy men [27, 28]. Perez-Pozo et al. [28] showed that lowering UA by allopurinol treatment prevented the increase in ambulatory BP.

There are some limitations to this study. First, our crosssectional study design does not eliminate potential causal relationships between UA, hsCRP, and MetS. Second, the prevalence rate of MetS, UA, and hsCRP categories is based on a single assessment of blood, which may introduce a misclassification bias. Third, we used BMI $\geq 25$ to classify individuals with visceral obesity because waist circumference measurements were not available, which might have caused an under or over estimation of the effect of visceral obesity on MetS [29]. In fact, the prevalence rate of MetS in women was higher than those generally reported for Japanese [30]. Fourth, we could not eliminate possible effects of the underlying diseases, and medication, especially diuretic use and antilipidemic drug use, on the results. These points need to be addressed again in a large population-based sample in a prospective manner.

In conclusion, the present study showed that combining UA and hsCRP levels are significantly associated with MetS, independent of other confounding factors in 
community-dwelling women. The underlying mechanism behind this relationship is unclear, but seems to be independent of traditional cardiovascular risk factors such as age, current smoking status, and alcohol consumption. For community-dwelling healthy women, prospective population-based studies are needed to investigate the mechanisms underlying this association to determine whether intervention, such as effective lifestyle modifications or medication (e.g., antihypertensive, antilipidemic, and diabetic medication) that decrease UA and hsCRP in adults [31], will decrease the risk of MetS.

Acknowledgments This work was supported in part by a Grant-inaid for Scientific Research from the Foundation for Development of Community (2011).

Conflict of interest The authors declare that they have no competing interests.

Open Access This article is distributed under the terms of the Creative Commons Attribution License which permits any use, distribution, and reproduction in any medium, provided the original author(s) and the source are credited.

\section{References}

1. K. Shiwaku, A. Nogi, K. Kitajima, E. Anuurad, B. Enkhmaa, M. Yamasaki, J.M. Kim, I.S. Kim, S.K. Lee, T. Oyunsuren, Y. Yamane, Prevalence of the metabolic syndrome using the modified ATP III definitions for workers in Japan, Korea and Mongolia. J. Occup. Health 47, 126-135 (2005)

2. C. Lorenzo, M. Okoloise, K. Williams, M.P. Stern, S.M. Haffner, San Antonio Heart Study: the metabolic syndrome as predictor of type 2 diabetes: the San Antonio Heart Study. Diabetes Care 26, 3153-3159 (2003)

3. A.M. McNeill, W.D. Rosamond, C.J. Girman, S.H. Golden, M.I. Schmidt, H.E. East, C.M. Ballantyne, G. Heiss, The metabolic syndrome and 11-year risk of incident cardiovascular disease in the atherosclerosis risk in communities study. Diabetes Care 28, 385-390 (2005)

4. Emerging Risk Factors Collaboration, S. Kaptoge, E. Di Angelantonio, G. Lowe, M.B. Pepys, S.G. Thompson, R. Collins, J. Danesh, C-reactive protein concentration and risk of coronary heart disease, stroke, and mortality: an individual participant meta-analysis. Lancet 375, 132-140 (2010)

5. Y. Saisho, H. Hirose, Y. Seino, I. Saito, H. Itoh, Usefulness of C-reactive protein to high-molecular-weight adiponectin ratio to predict insulin resistance and metabolic syndrome in Japanese men. J. Atheroscler. Thromb. 17, 944-952 (2010)

6. H. Tomiyama, Y. Koji, M. Yambe, K. Motobe, K. Shiina, Z. Gulnisa, Y. Yamamoto, A. Yamashina, Elevated C-reactive protein augments increased arterial stiffness in subjects with the metabolic syndrome. Hypertension 45, 997-1003 (2005)

7. C. Ruggiero, A. Cherubini, A. Ble, A.J. Bos, M. Maggio, V.D. Dixit, F. Lauretani, S. Bandinelli, U. Senin, L. Ferrucci, Uric acid and inflammatory markers. Eur. Heart J. 27, 1174-1181 (2006)

8. C. Zoccali, R. Maio, F. Mallamaci, G. Sesti, F. Perticone, Uric acid and endothelial dysfunction in essential hypertension. J. Am. Soc. Nephrol. 17, 1466-1471 (2006)
9. J. Sundström, L. Sullivan, R.B. D'Agostino, D. Levy, W.B. Kannel, R.S. Vasan, Relations of serum uric acid to longitudinal blood pressure tracking and hypertension incidence. Hypertension 45, 28-33 (2005)

10. C. Meisinger, W. Koenig, J. Baumert, A. Döring, Uric acid levels are associated with all-cause and cardiovascular disease mortality independent of systemic inflammation in men from the general population: the MONICA/KORA cohort study. Arterioscler. Thromb. Vasc. Biol. 28, 1186-1192 (2008)

11. G.K. Glantzounis, E.C. Tsimoyiannis, A.M. Kappas, D.A. Galaris, Uric acid and oxidative stress. Curr. Pharm. Des. 11, 4145-4151 (2005)

12. M. Koga, J. Murai, H. Saito, M. Mukai, S. Kasayama, Serum glycated albumin, but not glycated haemoglobin, is low in relation to glycemia in hyperuricemic men. Acta Diabetol. 47, 173-177 (2009)

13. R. Kawamoto, H. Tomita, Y. Oka, N. Ohtsuka, Relationship between serum uric acid concentration, metabolic syndrome and carotid atherosclerosis. Intern. Med. 45, 605-614 (2006)

14. W.T. Friedewald, R.I. Levy, D.S. Fredrickson, Estimation of the concentration of low-density lipoprotein cholesterol in plasma, without use of the preparative ultracentrifuge. Clin. Chem. 18, 499-502 (1972)

15. D.R. Matthews, J.P. Hosker, A.S. Rudenski, B.A. Naylor, D.F. Treacher, R.C. Turner, Homeostasis model assessment: insulin resistance and beta-cell function from fasting plasma glucose and insulin concentrations in man. Diabetologia 28, 412-419 (1985)

16. A.J. Hanley, K. Williamsm, M.P. Stern, S.M. Haffner, Homeostasis model assessment of insulin resistance in relation to the incidence of cardio-vascular disease: the San Antonio Heart Study. Diabetes Care 25, 1177-1184 (2002)

17. S.M. Grundy, J.I. Cleeman, S.R. Daniels, K.A. Donato, R.H. Eckel, B.A. Franklin, D.J. Gordon, R.M. Krauss, P.J. Savage, S.C. Smith Jr., J.A. Spertus, F. Costa, American Heart Association; National Heart, Lung, and Blood Institute: diagnosis and management of the metabolic syndrome: an American Heart Association/National Heart, Lung, and Blood Institute Scientific Statement. Circulation 112, 2735-2752 (2005)

18. T. Ota, T. Takamura, N. Hirai, K. Kobayashi, Preobesity in World Health Organization classification involves the metabolic syndrome in Japanese. Diabetes Care 25, 1252-1253 (2002)

19. X. Ye, Z. Yu, H. Li, O.H. Franco, Y. Liu, X. Lin, Distributions of C-reactive protein and its association with metabolic syndrome in middle-aged and older Chinese people. J. Am. Coll. Cardiol. 49, 1798-1805 (2007)

20. S.D. Anker, W. Doehner, M. Rauchhaus, R. Sharma, D. Francis, C. Knosalla, C.H. Davos, M. Cicoira, W. Shamim, M. Kemp, R. Segal, K.J. Osterziel, F. Leyva, R. Hetzer, P. Ponikowski, A.J. Coats, Uric acid and survival in chronic heart failure: validation and application in metabolic, functional, and hemodynamic staging. Circulation 107, 1991-1997 (2003)

21. T. Wang, Y. Bi, M. Xu, Y. Huang, Y. Xu, X. Li, W. Wang, G. Ning, Serum uric acid associates with the incidence of type 2 diabetes in a prospective cohort of middle-aged and elderly Chinese. Endocrine 40, 109-116 (2011)

22. G.S. Hotamisligil, Inflammatory pathways and insulin action. Int. J. Obes. Relat. Metab. Disord. 27(Suppl 3), S53-S55 (2003)

23. T. Montalcini, G. Gorgone, C. Gazzaruso, G. Sesti, F. Perticone, A. Pujia, Relation between serum uric acid and carotid intimamedia thickness in healthy postmenopausal women. Intern. Emerg. Med. 2, 19-23 (2007)

24. D.H. Kang, S.K. Park, I.K. Lee, R.J. Johnson, Uric acid-induced C-reactive protein expression: implication on cell proliferation and nitric oxide production of human vascular cells. J. Am. Soc. Nephrol. 16, 3553-3562 (2005) 
25. T. Nakagawa, K.R. Tuttle, R.A. Short, R.J. Johnson, Hypothesis: fructose-induced hyperuricemia as a causal mechanism for the epidemic of the metabolic syndrome. Nat. Clin. Pract. Nephrol. 1, 80-86 (2005)

26. M. Mazzali, J. Hughes, Y.G. Kim, J.A. Jefferson, D.H. Kang, K.L. Gordon, H.Y. Lan, S. Kivlighn, R.J. Johnson, Elevated uric acid increases blood pressure in the rat by a novel crystal-independent mechanism. Hypertension 38, 1101-1106 (2001)

27. T. Nakagawa, H. Hu, S. Zharikov, K.R. Tuttle, R.A. Short, O. Glushakova, X. Ouyang, D.I. Feig, E.R. Block, J. Herrera-Acosta, J.M. Patel, R.J. Johnson, A causal role for uric acid in fructoseinduced metabolic syndrome. Am. J. Physiol. Renal. Physiol. 290, F625-F631 (2006)

28. S.E. Perez-Pozo, J. Schold, T. Nakagawa, L.G. Sánchez-Lozada, R.J. Johnson, J.L. Lillo, Excessive fructose intake induces the features of metabolic syndrome in healthy adult men: role of uric acid in the hypertensive response. Int. J. Obes. (Lond.) 34, 454-461 (2010)

29. R. Kawamoto, N. Ohtsuka, D. Ninomiya, S. Nakamura, Carotid atherosclerosis in normal-weight metabolic syndrome. Intern. Med. 46, 1771-1777 (2007)

30. E. Oda, R. Kawai, Reproducibility of high-sensitivity C-reactive protein as an inflammatory component of metabolic syndrome in Japanese. Circ. J. 74, 1488-1493 (2010)

31. C.H. Tsai, T.C. Li, C.C. Lin, H.S. Tsay, Factor analysis of modifiable cardiovascular risk factors and prevalence of metabolic syndrome in adult Taiwanese. Endocrine 40, 256-264 (2011) 